\title{
Antoine-Marin Lemierre, Théâtre
}

\section{Wilma Proglio}

\section{(2) OpenEdition}

\section{Journals}

\section{Edizione digitale}

URL: http://journals.openedition.org/studifrancesi/9230

DOI: 10.4000/studifrancesi.9230

ISSN: 2427-5856

\section{Editore}

Rosenberg \& Sellier

\section{Edizione cartacea}

Data di pubblicazione: 1 juin 2008

Paginazione: 192

ISSN: 0039-2944

\section{Notizia bibliografica digitale}

Wilma Proglio, «Antoine-Marin Lemierre, Théâtre», Studi Francesi [Online], 154 (LII | I) | 2008, online da 30 novembre 2015, consultato il 12 janvier 2021. URL: http://journals.openedition.org/studifrancesi/ 9230 ; DOI: https://doi.org/10.4000/studifrancesi.9230

Questo documento è stato generato automaticamente il 12 janvier 2021.

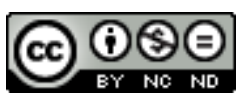

Studi Francesi è distribuita con Licenza Creative Commons Attribuzione - Non commerciale - Non opere derivate 4.0 Internazionale. 


\title{
Antoine-Marin Lemierre, Théâtre
}

\author{
Wilma Proglio
}

\section{NOTIZIA}

ANTOINE-MARIN LEMIERRE, Théâtre. Édition critique par France MARCHAL-NINOSQUE, Paris, Honoré Champion, 2006, pp. 463.

1 Questo volume contiene la riedizione integrale delle sette tragedie scritte e pubblicate da Lemierre: Hypermnestre, Idoménée, Artaxerce, Guillaume Tell, La veuve du Malabar e Barnevelt. L'autrice ripropone tali testi teatrali nella versione riprodotta nel $1810 \mathrm{da}$ René Perin nelle Euvres complètes di Lemierre. La studiosa procede inoltre ad un confronto tra le numerose stesure e revisioni delle tragedie del poeta francese, segnalando nelle note le varianti apportate dall'autore alle proprie opere nel corso dei decenni. La tragedia Barnevelt fa eccezione poiché è riportata interamente tanto nella versione trasmessa da Perin, quanto nella prima edizione risalente al 1784, poiché contraddistinte da una grande quantità di differenze. Nell'introduzione alle opere, l'autrice contestualizza Lemierre e la sua produzione drammaturgica nella seconda metà del Settecento sottolineando che, sotto l'influenza di Voltaire, il teatro prerivoluzionario rinuncia a mettere in scena grandi passioni per diventare strumento di diffusione degli ideali dei philosophes. L'ispirazione a soggetti greci, romani e mitologici persiste, ma cede progressivamente spazio alla volontà di trasmettere intenti e contenuti di natura politica, con evidenti riferimenti alla realtà del tempo. France Marchal-Ninosque definisce Lemierre come «le précurseur des dramaturges révolutionnaires» (p. 9), in quanto nelle sue pièces si avverte sensibilmente la trasformazione del teatro tragico operata dagli illuministi. I modelli imprescindibili di questo scrittore si possono undividuare in tre grandi figure: Corneille, per l'esaltazione della virtù, Voltaire, per il concetto di morale naturale, e Rousseau per il senso civico.

Dopo il grande successo di Hypermnestre nel 1758 Lemierre mette in scena Térée che, accolta con grande freddezza, non fu mai pubblicata. Con la successiva pièce Idoménée, Lemierre ritrova il favore del pubblico e dimostra il suo debito verso i philosophes, 
aprendosi a tematiche quali la legge naturale ed il rifiuto del fanatismo religioso. Dopo Artaxerce, ultima tragedia ancora legata a modelli tradizionali, inizia la fase più innovativa del teatro di Lemierre, con la scelta ormai esclusiva di soggetti storici. Guillaume Tell, La veuve du Malabar e Barnevelt, infatti, non si presentano più come «école des bonnes mœurs», ma come "écoles des citoyens» (p. 18). L'apprezzamento delle prime due da parte del pubblico avviene solo a distanza di anni, nel momento in cui Lemierre le ripropone con l'ausilio di espedienti scenici di grande impatto (quali Tell che trafigge la mela posta sulla testa del figlio e la vedova rapita dal rogo al quale è destinata). France Marchal-Ninosque sottolinea però che questo nuovo consenso è determinato non solo dalla ricerca di spettacolarità da parte di Lemierre, ma anche dalla sua sempre maggior adesione allo spirito ed ai valori morali e civili dell'illuminismo. Guillaume Tell è una tragedia dal carattere innovativo perché ha come protagonista un semplice contadino ma anche per l'accesa critica che muove al potere fondato sul diritto divino. Con La Veuve du Malabar si conferma ed accentua la condivisione da parte di Lemierre degli ideali di tolleranza, religione naturale e lotta alla superstizione propri degli illuministi. Dopo Céramis, mai data alle stampe, arriva Barnevelt, che è l'ultima pièce del drammaturgo francese. In quest'opera, il cui protagonista si configura come l'alter ego di Socrate, abbondano le disquisizioni religiose, politiche e filosofiche. Con Barnevelt Lemierre giunge a concepire una tragedia senza azione, siglando l'ultima tappa di un percorso artistico che parte dallo spettacolo, passa attraverso lo spettacolare e ha il suo compimento nel dibattito filosofico. Nella concezione drammaturgica di Lemierre, nutritasi del pensiero dei philosophes, il teatro è ormai una sorta di rito collettivo, «le lieu et le prétexte d'une sociabilité salvatrice, qui garantit le sentiment et l'humanité» (p. 27). 